Bull. Mater. Sci., Vol. 8, No. 4, Qctober 1986, pp. 439-448.

(C) Printed in India.

\title{
Liquid phase epitaxy growth of GaAs:Si by temperature difference method
}

\author{
C C WEI, Y K SU, C C CHANG and S C LU \\ Research Institute of Electronic and Electrical Engineering, National Cheng Kung \\ University, Tainan, Taiwan, Republic of China \\ MS received 26 October 1985
}

\begin{abstract}
The LPE growth of a horizontal sliding system by temperature difference method is used to grow single and multiple layers of GaAs compounds from dilute solution. The weight ratio of $\mathrm{Si}$ to $\mathrm{Ga}$ solvent is $10^{-4} \mathrm{wt} \%$. The growth rate, surface morphology, carrier concentration and Hall mobility are studied. Relationship between the above properties and the growth temperature and temperature difference $(\Delta T)$ is also discussed. In general, the present results appear quite consistent with the diffusion limited model. The growth rate can be precisely controlled. The stability of the solid-liquid interface can be obtained in the epilayer growth at a constant temperature of the system which can avoid the effect of constitutional supercooling. Under proper control, a perfect epilayer and multiple smooth layers can be obtained.
\end{abstract}

Keywords. Liquid phase epitaxy; GaAs:Si doping; temperature difference method; growth rate; surface morphology; carrier concentration; Hall mobility.

\section{Introduction}

Liquid phase epitaxy (LPE) is a technique normally used to grow single or multiple layers of III-V compound semiconductor materials from dilute solution. It can also be used to grow other materials, such as II-VI compounds and magnetic materials, and offers good quality epilayers for devices such as injection lasers, solar cells, varactor, LED and FET etc.

The steady state temperature difference method with horizontal sliding boat system was adopted in this experiment (Nishizawa and Okuno 1978). This technique is easier for temperature control compared with the transient method. The desired thickness of epilayers can be obtained by precisely controlling the growth time. The other advantage associated with this method is that constitutional supercooling can be avoided (Long et al 1974; Tiller 1968). In this experiment, silicon was used as the $n$ type dopant. The weight ratio of Si to Ga solvent was $10^{-4} \mathrm{wt} \%$. The Cr-doped semiinsulated GaAs wafer was used for substrate which was oriented on the $(100)$ crystal plane. Gallium was used as a solvent and GaAs polycrystal wafer was adopted as the source.

The growth rate, surface morphology, Hall mobility and carrier concentration were measured. Relationship between the above properties and growth temperature and $\Delta T$ (temperature difference between substrate and source) is also discussed.

The growth temperature and temperature difference ranged from $650^{\circ} \mathrm{C}$ to $800^{\circ} \mathrm{C}$ and from $4.5^{\circ} \mathrm{C}$ to $25.7^{\circ} \mathrm{C}$ respectively. The thickness of epilayer ranged from $1 \mu \mathrm{m}$ to $20 \mu \mathrm{m}$. 


\section{Growth apparatus and measurements}

The schematic diagram of the apparatus is shown in figure 1. The principal components are graphite boat, quartz tube, gold-coating transparent furnace, $\mathrm{H}_{2}$ purifier, vacuum system and exhaust system. Small quartz tubes were used as pushpull rod, graphite boat holder and thermal couple protector. Since temperature difference method was adopted (Nishizawa and Okuno 1978) the tungsten filament should be designed and wound around crucibles as heater. Certainly, a small cylindrical quartz tube was needed to cover the environment of graphite crucible to obtain a more uniform temperature distribution.

Gold-coating transparent furnace can be tuned to a constant temperature within $\pm 1^{\circ} \mathrm{C}$ over $70 \%$ of its length. The boat was set in the middle of the furnace for most stable temperature. Only one zone was needed.

Vacuum system had a cold trap with liquid nitrogen for preventing the oil vapour from contaminating the system.

After loading the boat and substrate, the reactor was flushed with flowing $\mathrm{H}_{2}$, evacuated and then backfilled with purified $\mathrm{H}_{2}$. A slow flowing $\mathrm{H}_{2}$ (about 0.5 litres/ $\mathrm{min}$ ) was used as purge $(30 \mathrm{~min})$ and the furnace was then moved into the position of boat. The furnace temperature was increased gradually to the growth temperature. After the stable operating temperature was reached, $\Delta T$ was established between substrate and source with AC power supply. A few minutes later, the substrate was pushed to contact source solution and the desired LPE layers were grown. During the growth run, the variation of the system temperature was kept within $\pm 0.5^{\circ} \mathrm{C}$ or less. After the growth run ended, the substrate was pushed out of the solution, the furnace moved away and the boat cooled to room temperature. Hydrogen flow stopped and then the growth was finished.

When the epilayer was grown, the surface morphology and cleavage surface of the epilayer were examined by optical microscopy. The carrier concentration and Hall

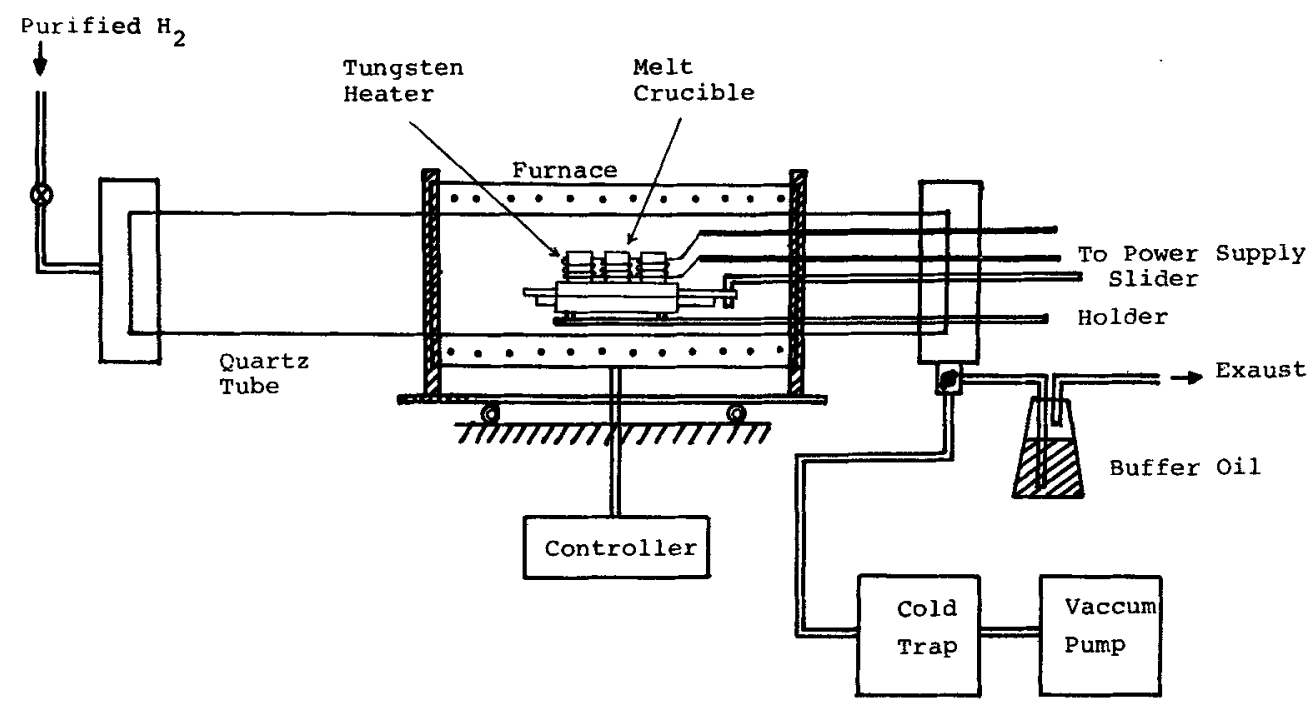

Figure 1. The apparatus of horizontal system for temperature difference method. 
mobility was measured with van der Pauw measurement and Hall effect. The multilayer $\mathrm{Ge} / \mathrm{Au} / \mathrm{Ni}$ (about $400 \AA / 2500 \AA / 400 \AA$ ), evaporated onto the wafer surface, was used for ohmic contacts.

\section{Results and discussion}

\subsection{Growth rate}

With a solution temperature of $704 \cdot 5-725 \cdot 7^{\circ} \mathrm{C}$, a substrate temperature of $700^{\circ} \mathrm{C}$ and a growth time of $4 \mathrm{hr}$, the thickness vs temperature difference $\Delta T$ between the source and the substrate is shown in figure 2. The experimental data are compared with theoretical values (Long et al 1974; Hsieh 1980). It can be shown that the thickness of epilayer increases as $\Delta T$ is increased. The furnace temperature was varied from $650^{\circ} \mathrm{C}$ to $800^{\circ} \mathrm{C}(\Delta T=18.8 \mathrm{C}$, growth time $=1 \mathrm{hr})$ and the thickness vs growth temperature is shown in figure 3. It is assumed that the diffusion constant is determined by growth temperature $\left(T_{G}\right)$ (dashed curve) and that it is determined by growth temperature and temperature difference between the source and the substrate (i.e. $T_{G}+\Delta T$ ) (dashed line b). The experimental data in figure 2 are more consistent in the latter case.

The growth rate of epilayer was apparently proportional to the growth time in our measurement (see figure 4). Further, the carrier concentration showed a strong dependence on the value of $\Delta T$. Two interesting experimental results are shown in figure 5. Figure 5(a) shows that two layers were grown on substrate in the same solution and at the same growth temperature but $\Delta T$ was different during the epilayer growth. The first and the second layers were grown with a temperature difference of $25.7^{\circ} \mathrm{C}$ and $11.2^{\circ} \mathrm{C}$ respectively for $2 \mathrm{hr}$. The growth temperature was set at $700^{\circ} \mathrm{C}$ and the height of the solution was $0.34 \mathrm{~cm}$. The thickness of the second layer was greater than the normal growth, because the temperature difference was

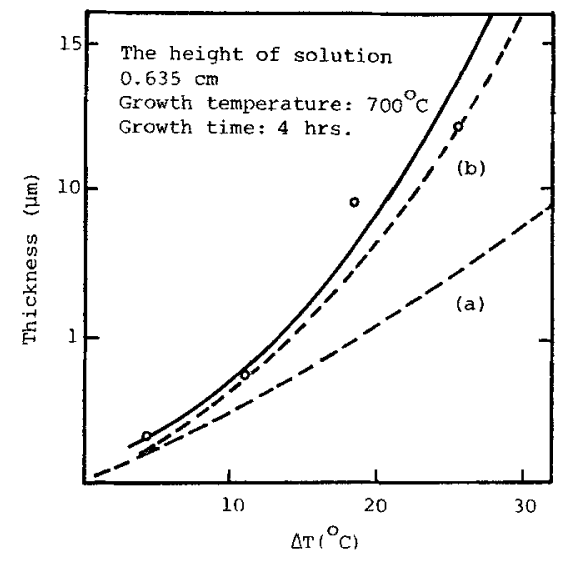

Figure 2. Epilayer thickness vs temperature difference $(\Delta T)$ curve. The dashed lines are the theoretical data and the solid line is the experimental data.

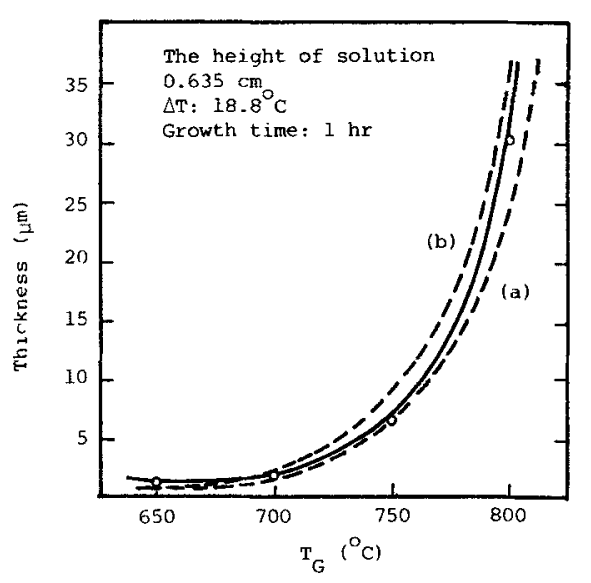

Figure 3. Epilayer thickness vs growth temperature curve. The dashed lines are the theoretical data and the solid line is the experimental data. 


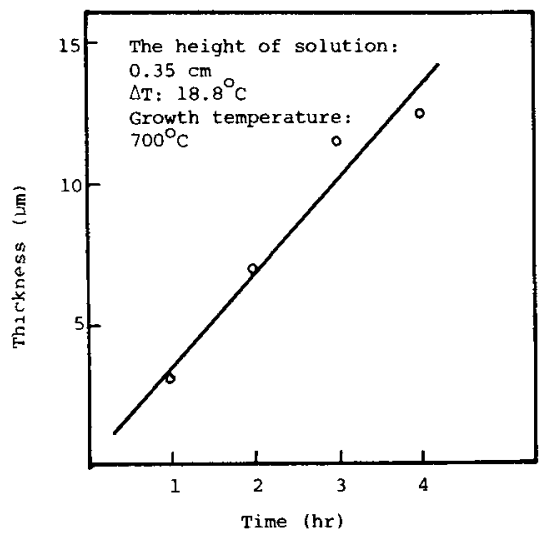

Figure 4. Epilayer thickness vs time curve.
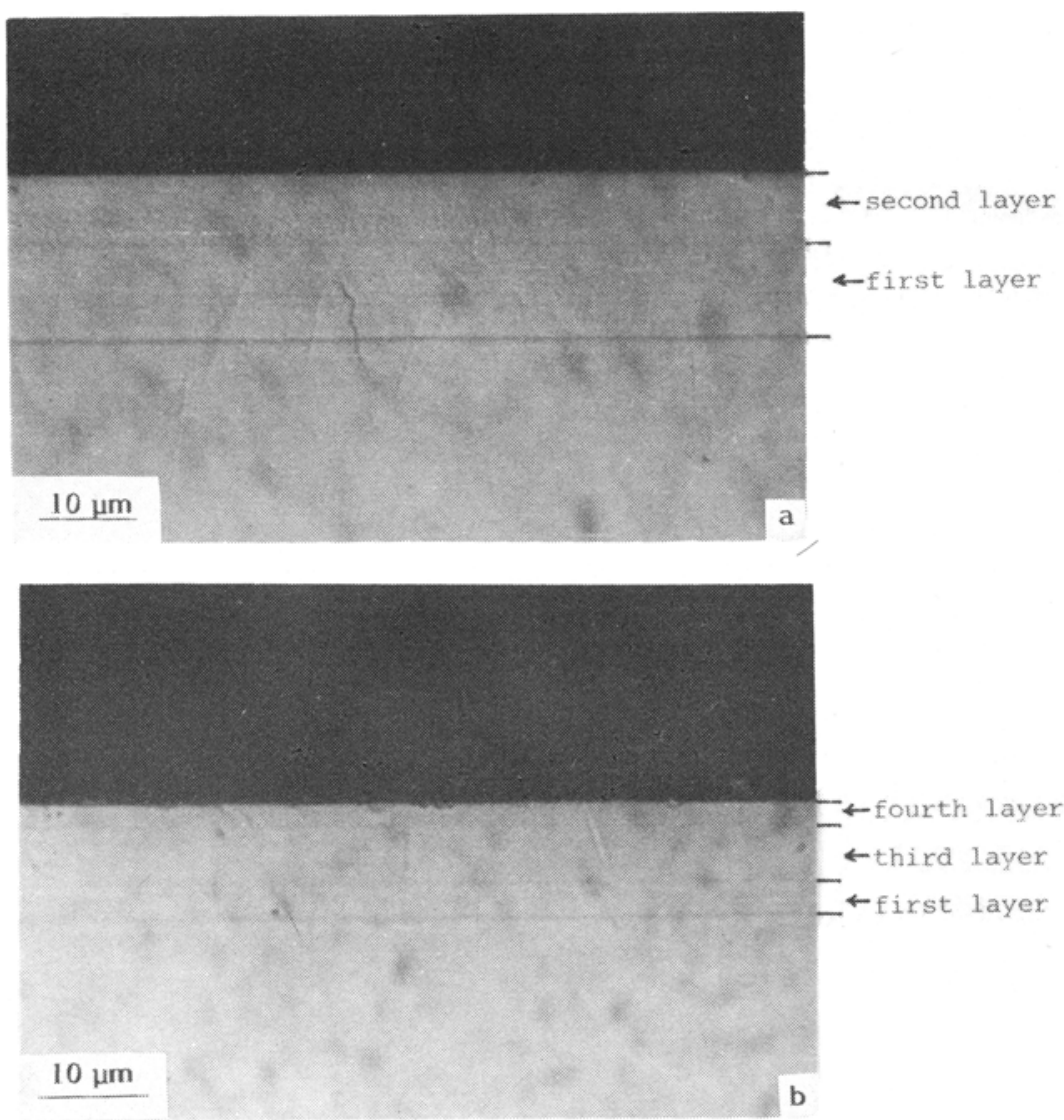

Figure 5. Cleavage surface of grown layer. (a) Double epilayers $\left(T_{G}=700^{\circ} \mathrm{C}, W=0.34 \mathrm{~cm}\right.$, $\Delta T: t=25.7^{\circ} \mathrm{C}: 2 \mathrm{hr}$ then $\left.11.2^{\circ} \mathrm{C}: 2 \mathrm{hr}\right)$ (b) Multilayer $\left(T_{G}=700^{\circ} \mathrm{C}, W=0.34 \mathrm{~cm}\right.$, $\Delta T: t=25 \cdot 7^{\circ} \mathrm{C}: 1 \mathrm{hr}, 11 \cdot 2^{\circ} \mathrm{C}: 1 \mathrm{hr}, 18 \cdot 8^{\circ} \mathrm{C}: 1 \mathrm{hr}$ then $\left.4 \cdot 5^{\circ} \mathrm{C}: 1 \mathrm{hr}\right)$. 
reduced from $25 \cdot 7^{\circ} \mathrm{C}$ to $11.2^{\circ} \mathrm{C}$ producing the condition of equilibrium cooling or step cooling in the solution.

A similar condition is shown in figure $5 \mathrm{~b}$. The temperature difference was $25 \cdot 7$, $11 \cdot 2,18.8$ and $4.5^{\circ} \mathrm{C}$ respectively for $1 \mathrm{hr}$ during each growth. Here, it appears that the fourth layer is much thicker than the normal growth, while the first layer is quite thinner than the normal growth, although the secondary layer has disappeared. Melt back etching seems to have occurred when the temperature difference changed from $11 \cdot 2^{\circ} \mathrm{C}$ to $18 \cdot 8^{\circ} \mathrm{C}$

\subsection{Electric characteristics of epilayers}

Figure 6 shows the dependence of resistivity and Hall mobility on carrier concentration. The dashed line from Sze (1981) shows the dependence of resistivity and Hall mobility on impurity concentration which can be compared with our experimental data. The Hall mobility and the resistivity of experimental data are lower than the comparative values of dashed lines. Perhaps it is influenced by the Si dopant because $\mathrm{Si}$ is an amphoteric impurity in GaAs layers (Casey and Panish 1978). Since carrier concentration is $n=N_{D}-N_{A}$ for n-type material and the impurity

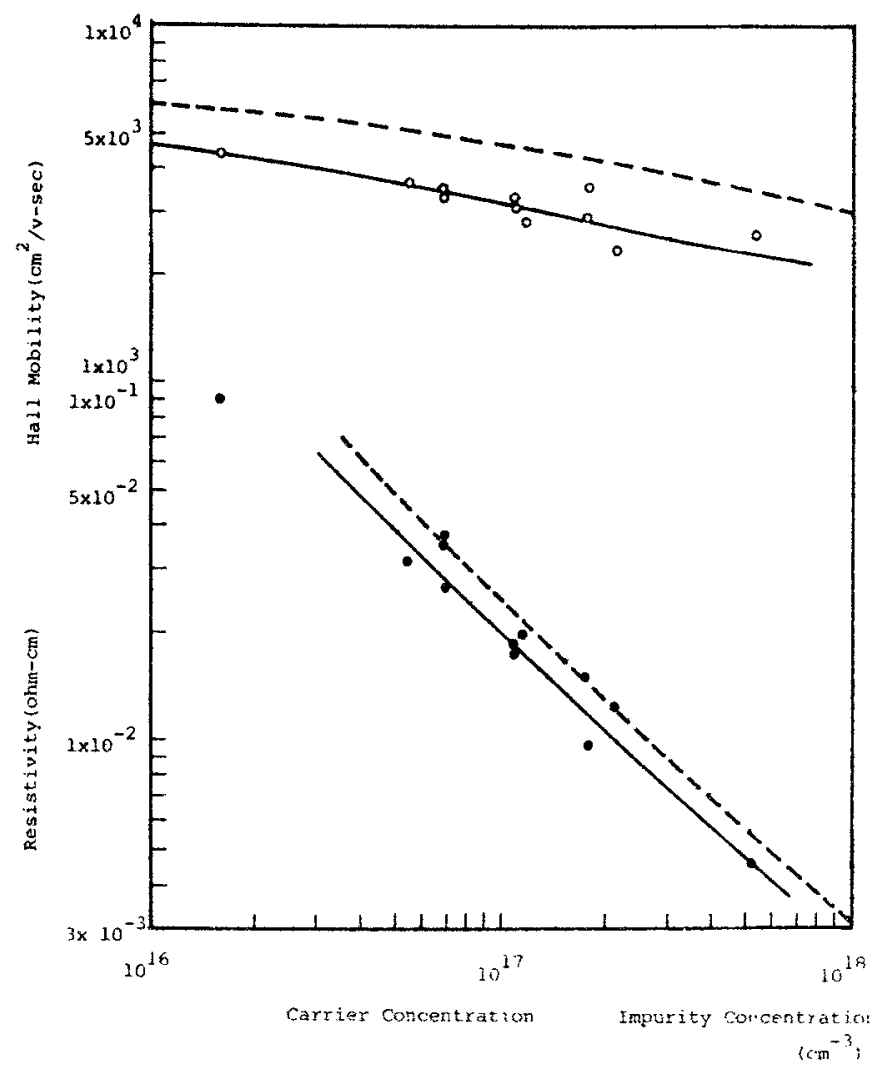

Figure 6. Dependence of resistivity and Hall mobility on carrier concentration (small circles) and impurity concentration (dashed lines). 
concentration is $C_{B}=N_{D}+N_{A}$, the carrier concentration is lower than impurity concentration. In our measurements the carrier concentration decreased with increasing growth temperature and $\Delta T$. It may be that the solution ahead of the advancing interface gets depleted of $\mathrm{Si}$, as a result of the limited diffusion of $\mathrm{Si}$ for faster growth rate. Certainly, the As vacancy may increase with temperature, but its influence is much less than the depletion effect of Si about $700^{\circ} \mathrm{C}$.

For the depletion effect of $\mathrm{Si}$, the carrier concentration decreased with increasing $\Delta T$ (figure 7). Hall mobility increased as $\Delta T$ increased (figure 8). The inhibition of constitutional supercooling also helps in increasing the Hall mobility. The saturation of this curve may be due to the increasing domination of As vacancy. The same is the

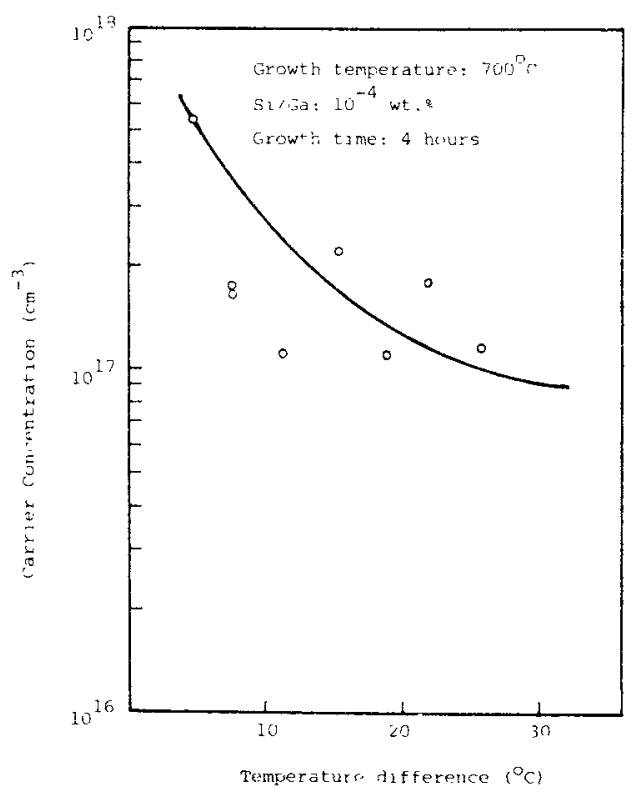

Figure 7. Dependence of carrier concentration on the temperature difference between source and substrate.

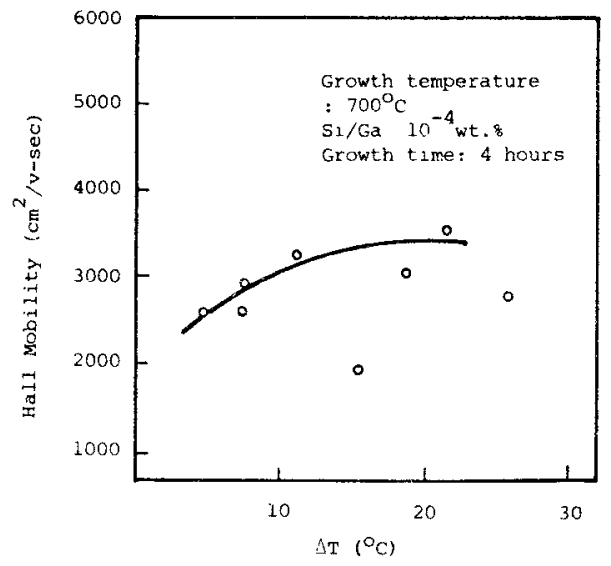

Figure 8. Dependence of Hall mobility on the temperature difference between source and substrate. 
reason for the changes of carrier concentration and Hall mobility followed by the variation of growth temperature. From figures 9 and 10 similar results can be found. When the variation of growth time was used as a parameter, a minimum carrier concentration and a maximum Hall mobility were measured in the vicinity of $2 \mathrm{hr}$ growth (figures 11 and 12).

\subsection{Surface morphology}

Figures 13(a) to 13(d) show some pictures of the surface grown at $700^{\circ} \mathrm{C}$ for $4 \mathrm{hr}$. The temperature difference was $4 \cdot 5,11 \cdot 2,18 \cdot 8$ and $25 \cdot 7^{\circ} \mathrm{C}$ respectively. On the scale of

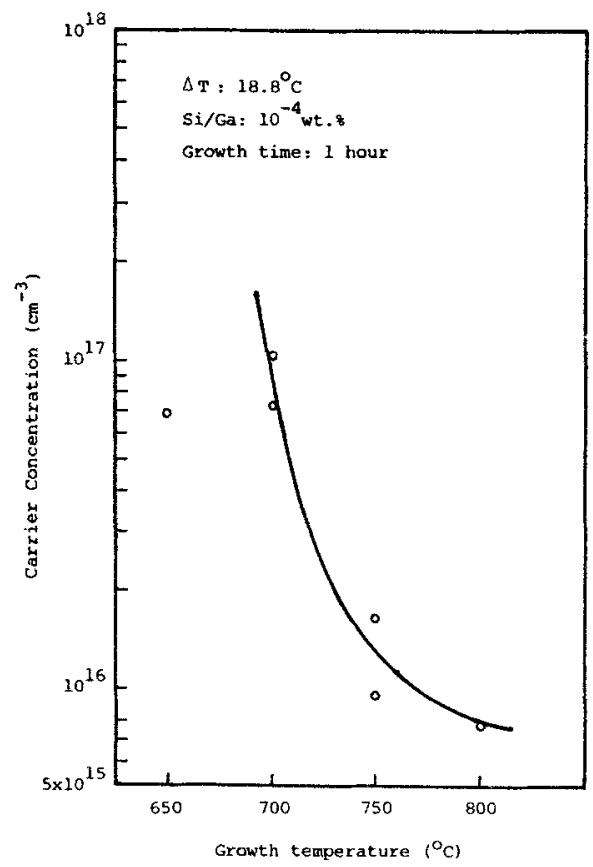

Figure 9. Dependence of carrier concentration on the growth temperature.

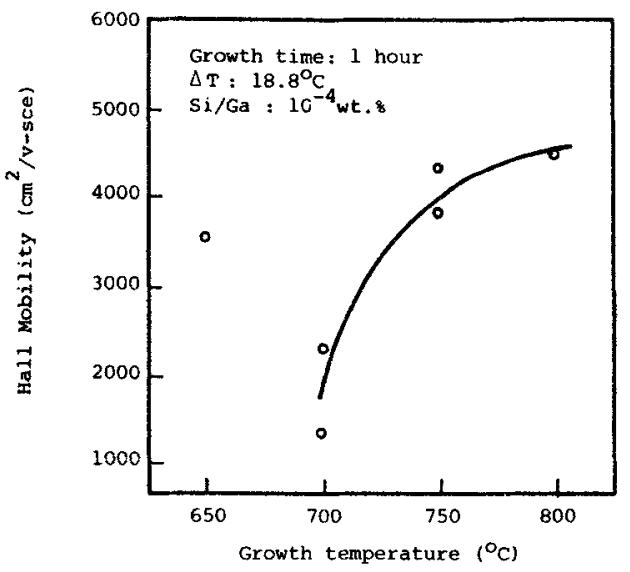

Figure 10. Dependence of Hall mobility on the growth temperature. 


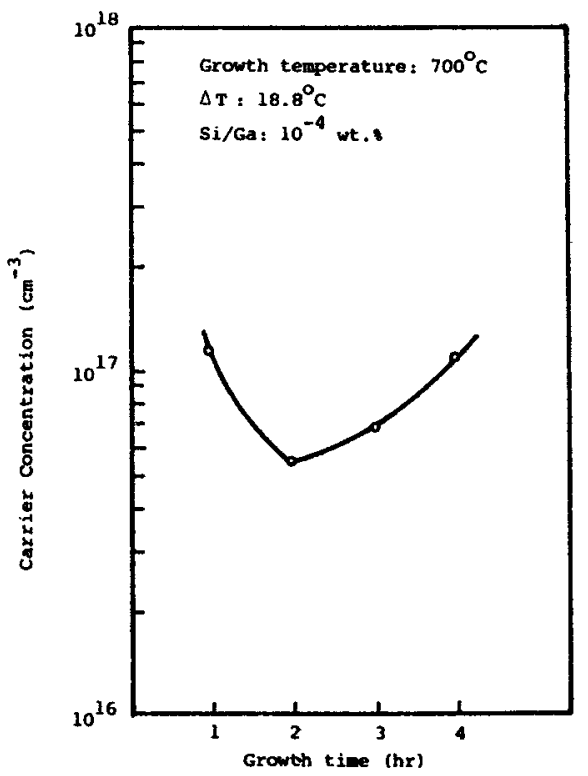

Figure 11. Dependence of carrier concentration on the growth time.

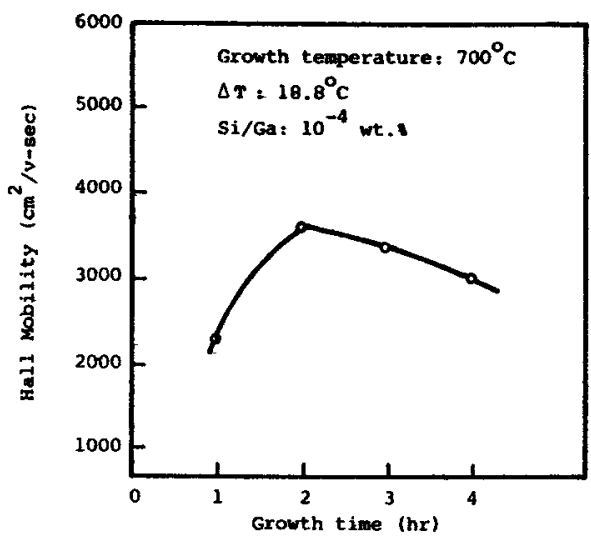

Figure 12. Dependence of Hall mobility on the growth time.

those photographs, the surface has a rough appearance although both to the eye and at higher magnifications the surface appeared smooth. Those photographs of higher magnification are shown in figures $13(\mathrm{e})$ and $13(\mathrm{f})$ with temperature difference of $4.5^{\circ} \mathrm{C}$ and $18.8^{\circ} \mathrm{C}$. It is found that with higher $\Delta T$, the surface morphology is better because the constitutional supercooling is inhibited more for the higher $\Delta T$.

\section{Conclusion}

The LPE growth was studied using the temperature difference method. The epilayer with uniform doping was grown. The results show that the electric characteristics and the thickness of the epilayer strongly depend on the growth temperature and the 

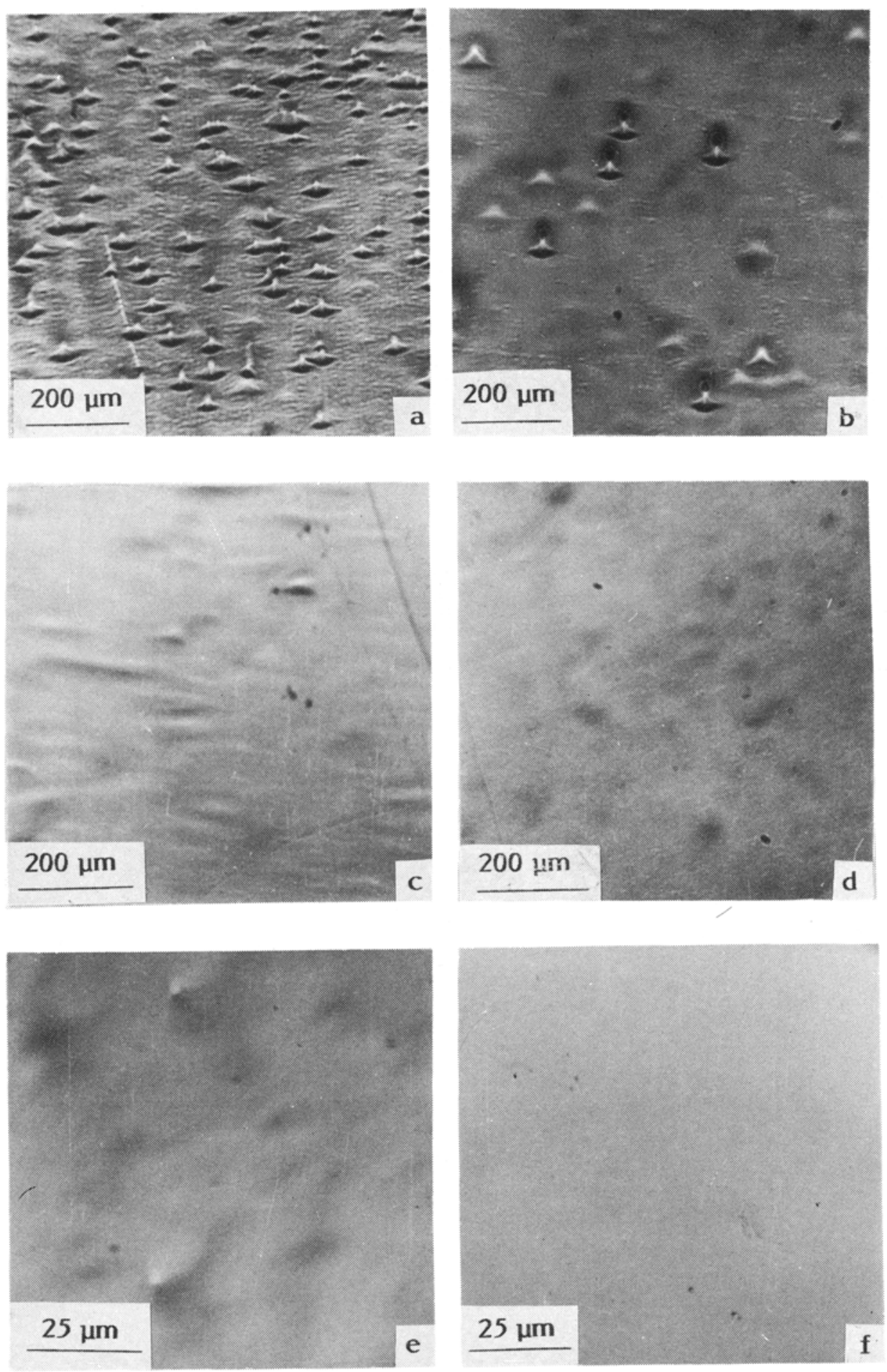

Figure 13. Photomicrographs of the substrate morphology $T_{G}=700^{\circ} \mathrm{C}, W=0.635 \mathrm{~cm}$, $t=4 \mathrm{hr}$, (a) $\Delta T=4 \cdot 5^{\circ} \mathrm{C}$, (b) $\Delta T=11 \cdot 2^{\circ} \mathrm{C}, \quad$ (c) $\Delta T=18 \cdot 8^{\circ} \mathrm{C}$, (d) $\Delta T=25 \cdot 7^{\circ} \mathrm{C}$, (e) higher magnification (8:1) of (a), (f) higher magnification (8:1) of (d). 
temperature difference. With proper control, a perfect epilayer and multiple smooth layers can be obtained.

Even the thickness is limited by edge effects. However, the uniformity of thickness is well away from the edge. Therefore by utilizing a larger size of substrate epilayer of better uniformity suitable for fabrication of devices can be obtained.

In general, diffusion limited model is consistent with this experiment. The growth rate can be controlled well. The stability of solid-liquid interface can be acquired by constant temperature of system, which can avoid the effect of constitutional supercooling.

As the solution ahead of the advancing interface becomes depleted of $\mathrm{Si}$, the reducing carrier concentration can be obtained at higher growth rate. Due to this effect, it increases the complication of epilayer growth. Although the variation of As vacancy influences the carrier concentration, depletion effect dominates the growth temperature about $700^{\circ} \mathrm{C}$. With proper control, a perfect epilayer can be obtained.

\section{Acknowledgements}

The authors gratefully acknowledge $\mathrm{Dr} \mathrm{T} \mathrm{S} \mathrm{Wu}$ for his fruitful discussions and suggestions. The authors also thank National Science Council, Republic of China for financial support of this research project.

\section{References}

Casey Jr H C and Panish M B 1978 Heterostructure lasers, Part B (New York: Academic Press) p 109 Hsieh J J 1980 Handbook on semiconductors (eds) T S Moss and S P Keller (Amsterdam, New York, Oxford: North-Holland) Vol. 2, p 418

Long S I, Ballantyne J M and Eastman L F 1974 J. Cryst. Growth 2613

Nishizawa J and Okuno Y 1978 RIEC Technical Report TR-41, April

Sze S M 1981 Physics of semiconductor devices (New York: John Wiley) pp 29-33

Tiller W A 1968 J. Cryst. Growth 269 